\title{
TLR4/Asp299Gly, CD14/C-260T, plasma levels of the soluble receptor CD14 and the risk of coronary heart disease: The PRIME Study
}

\author{
PE Morange ${ }^{1,2}$, L Tiret ${ }^{2}$, N Saut ${ }^{1}$, G Luc $^{3}$, D Arveiler $^{4}$, J Ferrieres $^{5}$, P Amouyel $^{6}$, A Evans ${ }^{7}$, \\ P Ducimetiere $^{8}$, F Cambien ${ }^{2}$, I Juhan-Vague ${ }^{*, 1}$ on behalf of the PRIME Study group
}

\begin{abstract}
${ }^{1}$ Hematology Laboratory, CHU Timone, Inserm U626, Faculty of Medicine, Marseille, France; ${ }^{2}$ INSERM U525, Faculté de Médecine Pitié-Salpétrière, Paris, France; ${ }^{3}$ Department of Atherosclerosis, INSERM UR545, Institut Pasteur de Lille, Lille, France; ${ }^{4}$ The Strasbourg MONICA Project, Department of Epidemiology and Public Health, Faculty of Medicine, Strasbourg, France; ${ }^{5}$ The Toulouse MONICA Project, INSERM U558, Department of Epidemiology, Paul SabatierToulouse Purpan University, Toulouse, France; ${ }^{6}$ The Lille MONICA Project, INSERM U508, Institut Pasteur de Lille, France; ${ }^{7}$ The Department of Epidemiology and Public Health, Queen's University of Belfast, Northern Ireland, UK; ${ }^{8}$ INSERM U258, Hôpital Paul Brousse, Villejuif, France
\end{abstract}

TLR4 and CD14 are two components of the LPS receptor complex, which are considered to play a key role in the pathogenesis of atherosclerosis. TLR4/Asp299Gly and CD14/C-260T polymorphisms are thought to modulate the activity of this complex. The aim of the study was to examine the association between the TLR4/Asp299Gly and CD14/C-260T polymorphisms, plasma levels of the soluble receptor CD14 (sCD14), and the incidence of coronary heart disease (CHD) in a prospective cohort (the PRIME Study) of 9758 healthy men aged 50-59 years recruited in France and Northern Ireland. A nested case-control design was used, comparing the 249 participants who developed a CHD event during the 5-year follow-up with 492 population- and age-matched control subjects. The two polymorphisms were genotyped and baseline plasma concentrations of sCD14 were measured. None of the two polymorphisms, or sCD14 levels, either considered alone or in combination, were associated with the risk of CHD. The CD14/C-260T allele was associated with increased plasma concentrations of soluble thrombomodulin and vascular cell adhesion molecule-1 and, to a lesser extent, sCD14. No relationship was observed between the TLR4 polymorphism and, any of the inflammatory and endothelial markers measured. The TLR4/Asp299Gly and CD14/C-260T polymorphisms and plasma SCD14 concentrations do not appear as significant predictors of the risk of CHD in healthy individuals.

European Journal of Human Genetics (2004) 12, 1041-1049. doi:10.1038/sj.ejhg.5201277

Published online 15 September 2004

Keywords: TLR4; CD14; polymorphism; coronary disease; inflammation

*Correspondence: $\operatorname{Dr}$ I Juhan-Vague, Hematology Laboratory, CHU Timone, Inserm U626, Faculty of Medicine, 13385 Marseilles Cedex 5, France. Tel: + 334913860 49; Fax: + 334912543 36;

E-mail: ijuhan@ap-hm.fr

The PRIME Study Group is listed in Appendix A1

Received 17 June 2004; revised 21 July 2004; accepted 27 July 2004
Introduction

Immune and inflammatory mechanisms are considered to play a key role in the pathogenesis of atherosclerosis. ${ }^{1,2}$ The toll-like receptor (TLR) 4 is a receptor for lipopolysaccharide (LPS) and heat-shock proteins, molecules known to initiate an innate immune response, including the production of proinflammatory cytokines by macrophages and adhesion molecules in endothelial cells through nuclear 
factor (NF) $-\kappa \mathrm{B}$ activation. ${ }^{3,4}$ TLR4 has recently been described in macrophages and endothelial cells in the atherosclerotic plaque. ${ }^{5}$ It has been shown that a common missense mutation Asp299Gly affecting the extracellular domain of the TLR4 receptor is associated with a blunted response to inhalated LPS in humans. ${ }^{6}$ Several studies have investigated the association of this polymorphism with the development of atherosclerosis. Three of them reported that the $\mathrm{Gly}^{299}$ allele of the TLR4 polymorphism might confer protection against atherosclerosis and its complications, $^{7-9}$ whereas another did not find any association between the TLR4 polymorphism and the susceptibility to and severity of coronary disease. ${ }^{10}$

Several lines of evidence suggest that TLR4 cannot function as a singular binding and signalling receptor but belongs to an 'LPS signalling complex' ${ }^{11}$ One likely component of this putative LPS receptor complex is CD14, which is present in macrophages (CD14 membrane bound, mCD14) and in plasma as a soluble protein (sCD14) that promotes the response of endothelial cells, which do not express mCD14. ${ }^{12}$ Multiple biochemical and genetic studies support the concept that CD14 binds to LPS, but does not participate in the signalling of the NF- $\kappa \mathrm{B}$ pathway. ${ }^{13}$ Nonetheless, CD14 knockout mice have been shown to be highly resistant to LPS ${ }^{14}$ and TLR4-mediated $\mathrm{NF}-\kappa \mathrm{B}$ activation by LPS could be enhanced by the addition of sCD14, ${ }^{15}$ supporting a role of CD14 in the LPS receptor complex. A C-260T substitution located in the promoter region of the CD14 gene is thought to modulate the capacity to elicit inflammation through the regulation of CD14 gene expression and plasma sCD14 levels. ${ }^{16-18}$ Studies investigating the association between the CD14/ C-260T polymorphism and coronary disease brought conflicting results. The $\mathrm{T}$ allele was found to be associated with a higher risk of myocardial infarction (MI) in three case-control studies. ${ }^{17,19,20}$ Conversely, the CC genotype was associated with an increased incidence of incident coronary occlusion and increased carotid artery intimamedia thickness (IMT). ${ }^{21,22}$ One prospective study ${ }^{23}$ and three retrospective ones ${ }^{18,24,25}$ did not find any association between the polymorphism and the risk of coronary events. No relationship was found between plasma concentrations of sCD14 and stable coronary artery disease or carotid IMT. $^{24,26}$

Given the potential interaction between TLR4 and CD14 in mediating signal transduction of innate immunity, we investigated the relation of these two polymorphisms, as well as sCD14 plasma levels, with the risk of coronary heart disease (CHD) and the plasma levels of inflammatory markers. We used a nested case-control study design within the PRIME prospective cohort. PRIME is a large multicentre cohort with a 5-year follow-up, aimed at investigating the role of different biological and genetic markers in the development of CHD in France and Northern Ireland.

\section{Material and methods}

The PRIME Study (Prospective Epidemiological Study of Myocardial Infarction) has been described in detail. ${ }^{27}$ It is a population-based prospective study set-up to investigate risk factors for $\mathrm{CHD}$ and, more particularly, to identify those that might explain the difference in CHD incidence between France and Northern Ireland. From 1991 to 1994, 9758 men aged 50-59 years with no previous CHD events, living in the area of Lille, Strasbourg, Toulouse in France and Belfast in Northern Ireland, were recruited and followed up for over 5 years. At entry, venous blood was collected after a 12-h fast into siliconised vacutainer tubes (Vacutainer, Becton Dickinson) containing $0.11 \mathrm{M}$ trisodium citrate (1 volume). Platelet-poor plasma was obtained by centrifugation at $4500 \mathrm{~g}$ and $20^{\circ} \mathrm{C}$ for $15 \mathrm{mn}$. Without delay, aliquots of plasma were transferred into plastic tubes and frozen on-site to $-80^{\circ} \mathrm{C}$, and were then sent weekly to the central laboratory at the Pasteur Institute of Lille, where they were stored in liquid nitrogen until analysis.

For subjects reporting a possible clinical event, information was sought directly from the hospital or general practitioners' files. All details of ECG, hospital admissions, enzymes, surgical operations, angioplasty, treatment, etc were collected and classified according to MONICA (Monitoring Trends and Determinants in Cardiovascular Disease) criteria. $^{28}$ Death certificates were also used to complete information on the cause of death. A medical committee provided independent validation and classification of coronary events. CHD categories retained for analysis were nonfatal MI or coronary death (grouped together as hard coronary event), and unstable angina pectoris or effort angina (grouped as angina pectoris), yielding a total number of cases of $317 .{ }^{29}$

The present study was carried out using a nested casecontrol design. Each case was matched with two agematched ( \pm 3 years) control subjects recruited in the same centre and on the same day ( \pm 3 days) as the corresponding case and free of $\mathrm{CHD}$ at the date of the coronary event of the case. Of the initial sample of 317 cases, 68 were not available for DNA analysis, either because they had not given their informed consent for the genetic part of the study or due to lack of DNA. When a case was not available for analysis, the two matched controls were excluded from the present study. When one or the two controls of a case were not available for the same reasons, they were replaced by other controls meeting the same matching criteria whenever possible. A total of 249 cases and 492 matched controls were used in the present study. Cases and controls included in the analysis did not significantly differ from those not included with respect to the main cardiovascular risk factors.

\section{sCD14 determination}

Stored plasma samples obtained at baseline were sent from the central plasma bank in dry ice to the Laboratory of 
Haemostasis of La Timone Hospital in Marseilles, France. Determination of sCD14 was performed with a commercially available ELISA from R\&D Systems (Minneapolis, MN, USA) according to the instructions available from the supplier. Blood specimens were analysed in blinded pairs, with the position of the case specimen randomly varied within pairs to reduce the possibility of systematic bias and minimize interassay variability. The interassay coefficient of variation was $10 \%$. The methods used to evaluate baseline lipid parameters, inflammation and endothelial markers have been described elsewhere. ${ }^{29-33}$

\section{Genotyping of TLR4/Asp299Gly and CD14/C-260T polymorphisms}

Genomic DNA was extracted from peripheral blood leucocytes by the salting-out method. ${ }^{34}$ The CD14/C260T polymorphism was genotyped by PCR-RFLP using restriction enzyme HaeIII. PCR was carried out in a $25 \mu \mathrm{l}$ reaction volume, using final concentrations of $200 \mathrm{nM}$ of each primer (forward: 5'-TAAGGCACTGAGGATCATCC-3'; reverse: 5'-GGCTTCACACTTGTGAACTC), $200 \mu \mathrm{M}$ of each dNTP, $75 \mathrm{ng}$ of genomic DNA, $3.5 \mathrm{mM} \mathrm{MgCl} 2$ and $0.25 \mathrm{U}$ of Taq DNA polymerase. Conditions were: 40 cycles consisting of denaturation at $94^{\circ} \mathrm{C}, 30 \mathrm{~s}$; annealing at $60^{\circ} \mathrm{C}, 45 \mathrm{~s}$ and elongation at $72^{\circ} \mathrm{C} 1 \mathrm{~min}$, followed by a final extension step at $72^{\circ} \mathrm{C}$ for $5 \mathrm{~min}$. The PCR product $(8 \mu \mathrm{l})$ was digested using $2 \mathrm{U}$ of $\mathrm{HaeIII}$ at $37^{\circ} \mathrm{C}$ and the digestion products were identified by migration on a $2 \%$ agarose gel stained with ethidium bromide. Digestion of the PCR product gives a $329 \mathrm{bp}$ product for the $\mathrm{T}$ allele and two products of 170 and $159 \mathrm{bp}$, respectively, for the $\mathrm{C}$ allele.

The TLR4/Asp299Gly polymorphism was genotyped by allele-specific PCR. The PCR reaction conditions were as for the CD14/C-260T polymorphism, except for the Taq polymerase for which $0.3 \mathrm{U}$ were used per reaction and the annealing temperature $\left(58^{\circ} \mathrm{C}\right)$. Two different mixtures were carried out with forward and reverse primers in each case (forward: 5'-TTTAGACTGTCCCTGAAC-3'; reverse: 5'AGATTTGAGTTTCAATGTGGG-3') plus the allele-specific primer, which corresponded to the analysed genotype (A allele: 5'-CAATTAAATAAGTCAATTATATC-3' and G: 5'AATTAAATAAGTCAATTATACC- $3^{\prime}$ ). Size of the forwardreverse product and the allele-specific were, respectively, 437 and $298 \mathrm{bp}$.

\section{Statistical analysis}

Allele frequencies were estimated by gene counting. Departure from Hardy-Weinberg equilibrium was tested separately in cases and controls and in each population by a $\chi^{2}$ with $1 \mathrm{df}$. Owing to the low frequency of the TLR4/ Gly $^{299}$ allele, rare homozygotes were pooled with heterozygotes for analysis. Mean levels of continuous variables were compared between cases and controls by ANOVA adjusted for population (France/Northern Ireland). Variables with a skewed distribution were log transformed before analysis. Conditional logistic regression analysis for matched case-control studies was used to investigate the association between outcome and explanatory variables. The analysis included 243 trios and six pairs of casescontrols. Since cases and controls were matched by population, all case-control comparisons were implicitly stratified according to population. The relative risks (RRs) and $95 \%$ CIs are reported. $P<0.05$ was considered significant. All computations were performed with SAS software, version 8.1 (SAS Institute).

\section{Results \\ Baseline characteristics}

During the 5-year follow-up period, the annual incidence of coronary events was two-fold higher in Northern Ireland than in France $\left(11.51 / 1000\right.$ vs $5.48 / 1000$ per year), ${ }^{29}$ resulting in an almost equal number of cases in the two cohorts despite the smaller size of the baseline cohort in Northern Ireland than in France $(n=2399$ and 7359, respectively). Table 1 shows the baseline clinical characteristics of the cases and controls included in the present analysis. Among the 249 cases, 128 (51.4\%) had suffered from a hard CHD event and 123 (49.4\%) from angina pectoris (two cases had suffered from both). As expected, initially healthy men who subsequently developed CHD (cases) were more likely at baseline to have a history of hypertension or diabetes, were more often smokers, and had an adverse lipid profile when compared to men who remained free of disease (controls). The effect of these conventional cardiovascular risk factors was similar in France and Northern Ireland.

\section{Correlation of sCD14 with other cardiovascular risk factors}

As outlined in Table 2, diabetes was associated with markedly increased concentrations of sCD14 $(P<0.001)$, consistently in France and Northern Ireland. This effect remained significant $(P=0.004)$ even after adjustment for C-reactive protein (CRP). In contrast, hypertension or smoking status did not significantly influence sCD14 levels. Correlations between plasma levels of sCD14 and continuous risk variables are reported in Table 3. sCD14 was not associated with body mass index or lipid parameters. It correlated with acute phase reactants such as CRP, fibrinogen and IL-6, but not with TNF- $\alpha$ or IL-18. With respect to endothelial cell markers, sCD14 correlated with soluble intercellular adhesion molecule (sICAM)-1 and soluble thrombomodulin (sTM), but not with soluble vascular cell adhesion molecule (sVCAM)-1, von Willebrand factor (vWF) or free tissue factor pathway inhibitor (f-TFPI). The correlation with inflammatory markers was of similar magnitude in France and Northern Ireland, whereas the relationship of sCD14 with sICAM-1 and sTM appeared stronger in Northern Ireland than in France, even though 
Table 1 Baseline characteristics of cases and controls included in the nested case-control study

\begin{tabular}{|c|c|c|c|}
\hline Characteristics & $\begin{array}{c}\text { Contro/s } \\
\text { (France/N. Ireland; } n=225 / 267 \text { ) }\end{array}$ & $\begin{array}{c}\text { Cases } \\
\text { (France/N. Ireland; } n=115 / 134)\end{array}$ & P-value \\
\hline $\begin{array}{l}\text { AGE }(Y) \\
\text { BMI }\left(\mathrm{kg} / \mathrm{m}^{2}\right) \\
\text { SBP }(\mathrm{mm} \mathrm{Hg}) \\
\text { DBP }(\mathrm{mm} \mathrm{Ha})\end{array}$ & $\begin{array}{r}55.1 \pm 0.1 \\
26.7 \pm 0.2 \\
134.6 \pm 0.9\end{array}$ & $\begin{array}{r}55.3 \pm 0.2 \\
27.1 \pm 0.2 \\
141.5 \pm 1.3\end{array}$ & $\begin{array}{l}0.5 \\
0.1 \\
<0.001\end{array}$ \\
\hline History (\%) & $83.7 \pm 0.6$ & $87.0 \pm 0.8$ & $<0.001$ \\
\hline $\begin{array}{l}\text { Hypertension } \\
\text { Diabetes mellitus }\end{array}$ & $\begin{array}{r}10.5 \\
3.4\end{array}$ & $\begin{array}{r}20.5 \\
7.6\end{array}$ & $\begin{array}{c}<0.001 \\
0.02\end{array}$ \\
\hline $\begin{array}{l}\text { Smoking status (\%) } \\
\text { Never } \\
\text { Former } \\
\text { Current }\end{array}$ & $\begin{array}{l}30.6 \\
41.5 \\
27.9\end{array}$ & $\begin{array}{l}19.7 \\
40.2 \\
40.2\end{array}$ & 0.002 \\
\hline $\begin{array}{l}\text { Lipid status } \\
\text { Total cholesterol }(\mathrm{g} / \mathrm{l}) \\
\text { HDL cholesterol }(\mathrm{g} / \mathrm{l}) \\
\text { Triglycerides }\left(\mathrm{g} / \mathrm{l}^{\star}\right.\end{array}$ & $\begin{array}{c}2.24 \pm 0.02 \\
0.47 \pm 0.005 \\
1.39(1.33-1.46)\end{array}$ & $\begin{array}{c}2.34 \pm 0.02 \\
0.43 \pm 0.007 \\
1.54(1.44-1.64)\end{array}$ & $\begin{array}{c}<0.001 \\
<0.001 \\
0.02\end{array}$ \\
\hline
\end{tabular}

$\mathrm{BMI}=$ body mass index, $\mathrm{SBP}=$ systolic blood pressure, $\mathrm{DBP}=$ diastolic blood pressure.

Data presented are percentages for categorical variables and population-adjusted mean \pm SEM for continuous variables or

*population-adjusted geometric means $(95 \% \mathrm{Cl})$ for log-transformed variables.

Table 2 Mean levels (SEM) of plasma sCD14 according to categorical risk factors ${ }^{a}$

\begin{tabular}{llll}
\hline & \multicolumn{1}{c}{ All } & \multicolumn{1}{c}{ France } & Northern Ireland \\
\hline Diabetes & $1.52(0.02)$ & $1.44(0.03)$ & $1.58(0.02)$ \\
$\quad$ No & $1.79(0.08)$ & $1.69(0.06)$ & $1.88(0.14)$ \\
Yes & 0.001 & 0.01 & 0.04 \\
P-value & & & \\
Hypertension & & & \\
$\quad$ No & $1.53(0.02)$ & $1.44(0.03)$ & $1.59(0.02)$ \\
Yes & $1.54(0.05)$ & $1.53(0.06)$ & $1.55(0.08)$ \\
P-value & 0.93 & 0.17 & 0.67 \\
Smoking & & & \\
$\quad$ Never & $1.52(0.03)$ & $1.52(0.06)$ & $1.54(0.04)$ \\
$\quad$ Former+current & $1.53(0.02)$ & $1.45(0.03)$ & $1.61(0.03)$ \\
P-value & 0.98 & 0.27 & 0.20 \\
\hline
\end{tabular}

Values are in $\mu \mathrm{g} / \mathrm{ml}$.

${ }^{a}$ Means are adjusted for case-control status, and additionally adjusted for population in the column 'all'.

the interaction did not reach significance $(P$ for interaction $=0.30$ and 0.62 for sICAM- 1 and sTM, respectively). Adjustment on CRP did not modify the relation between sCD14 and sICAM-1 or sTM.

Plasma levels of sCD14 and coronary risk

Baseline concentrations of sCD14 were not significantly different between individuals who experienced a coronary event during follow-up and those who did not, either in the whole cohort or when considering each country separately (Table 4). sCD14 concentrations were similar
Table 3 Pearson's correlation coefficients of sCD14 levels with lipid parameters, inflammatory markers and endothelial-cell-derived factors

\begin{tabular}{|c|c|c|c|}
\hline & All & France & Northern Ireland \\
\hline BMI & -0.02 & -0.02 & -0.01 \\
\hline Total cholesterol & 0.005 & -0.04 & 0.03 \\
\hline HDL cholesterol & 0.05 & 0.002 & 0.06 \\
\hline Triglycerides $^{a}$ & -0.004 & -0.04 & 0.03 \\
\hline$C R P^{a}$ & $0.19^{\star \star *}$ & $0.19^{* *}$ & $0.18^{* *}$ \\
\hline $\mathrm{IL}-6^{\mathrm{a}}$ & $0.09 *$ & $0.14^{*}$ & 0.05 \\
\hline Fibrinogen & $0.18^{\star * *}$ & $0.18^{* * *}$ & $0.20^{* *}$ \\
\hline TNF- $\alpha^{\mathrm{a}}$ & 0.03 & -0.02 & 0.08 \\
\hline $\mathrm{IL}-18^{\mathrm{a}}$ & 0.005 & 0.04 & -0.01 \\
\hline sICAM-1 ${ }^{\mathrm{a}}$ & $0.15^{* * *}$ & 0.08 & $0.20^{\star * *}$ \\
\hline SVCAM-1 $1^{a}$ & -0.02 & -0.11 & 0.05 \\
\hline Vwf & 0.07 & 0.08 & 0.06 \\
\hline sTM $^{\mathrm{a}}$ & $0.16^{\star * *}$ & 0.08 & $0.23^{* * *}$ \\
\hline f-TFPI & 0.07 & 0.07 & 0.06 \\
\hline
\end{tabular}

$\mathrm{BMI}=$ body mass index; $\mathrm{CRP}=\mathrm{C}$-reactive protein; IL-6 = interleukin- 6 ; TNF- $\alpha=$ tumour necrosis factor- $\alpha$; IL-18 =interleukin-18; sICAM$1=$ soluble intercellular adhesion molecule- $1 ; \quad$ sVCAM- $1=$ soluble vascular cell adhesion molecule- 1 ; $\mathrm{VWF}=$ von Willebrand factor; sTM=soluble thrombomodulin; f-TFPI = free-tissue factor pathway inhibitor-1.

${ }^{*} P<0.05 ;{ }^{* *} P<0.01 ;{ }^{* * *} P<0.001$.

Correlation coefficients are adjusted for case-control status, and additionally adjusted for population in the column 'all'.

${ }^{a}$ Variables were log-transformed for analysis.

among individuals with hard coronary events and those with angina pectoris $(1.53 \pm 0.02$ vs $1.54 \pm 0.04 \mu \mathrm{g} / \mathrm{ml}$; $P=0.96)$. Plasma concentrations of sCD14 were higher in Northern Ireland than in France, both in cases and in controls (Table 4). 
Table 4 Means (SEM) of plasma SCD14 in cases and controls and RR of coronary event associated with 1 SD increase of sCD14 level

\begin{tabular}{lccrr}
\hline & Controls & Cases & P-value* & $R R(95 \%$ CI) \\
\hline All & $1.53(0.02)$ & $1.55(0.03)$ & 0.18 & $1.15(0.94-1.40)$ \\
France & $1.45(0.03)$ & $1.48(0.04)$ & 0.14 & $1.27(0.93-1.73)$ \\
Northern Ireland & $1.58(0.03)$ & $1.59(0.04)$ & 0.63 & $1.07(0.82-1.39)$ \\
P-value* & $<0.001$ & $<0.001$ & & \\
\hline
\end{tabular}

Values are in $\mu \mathrm{g} / \mathrm{ml}$. In the line 'all', means and RR are adjusted for population.

${ }^{*} P$-value for difference between cases and controls.

${ }^{* *} P$-value for difference between France and Northern Ireland.

\section{Association of CD14 and TLR4 genotypes with conventional cardiovascular risk factors and plasma concentrations of inflammatory and endothelial markers}

The two genotypes were not associated with any of the conventional cardiovascular risk factors (hypertension, smoking status, diabetes, body mass index, total cholesterol and HDL cholesterol) (data not shown).

As. shown in Table 5, a weak association between the CD14/C-260 T polymorphism and sCD14 concentrations was observed, the $\mathrm{T}$ allele being associated with increased levels in a codominant manner $(P=0.05$ for the association when assuming additive allele effects). The CD14/C-260T polymorphism was also associated with CRP $(P=0.04)$, the $\mathrm{T}$ allele being associated with decreased levels of this marker. No relation was observed with TNF- $\alpha$ or fibrinogen. The CD14/C-260T polymorphism was associated with endothelial parameters such as sTM $(P=0.003)$ and sVCAM-1 $(P=0.003)$. After adjustment for CRP, the association between the C-260T polymorphism and sCD14 remained significant. Adjustment for sCD14 did not modify the relation between endothelial markers and the CD14 polymorphism.

No association was observed between the TLR4/Asp299Gly polymorphism and any of the inflammatory or endothelial markers studied (Table 5).

\section{Association of CD14 and TLR4 polymorphisms with coronary risk}

The genotype distributions of the CD14 and TLR4 polymorphisms did not deviate from Hardy-Weinberg expectations in any group or population (all $P>0.1$ ). Genotype and allele frequencies were similar in France and Northern Ireland (Table 6).

Genotype distributions of the CD14 polymorphism did not significantly differ between cases and controls, either in the whole cohort or in each country considered separately (Table 6). When splitting cases according to the type of event (hard CHD event and angina pectoris), no association was observed between either category and genotype (Table 6).

With respect to the TLR4 polymorphism, genotype distributions did not significantly differ between cases and controls in the whole sample (Table 6). However, carriers of the $\mathrm{Gly}^{299}$ allele were significantly more represented among cases with a hard CHD event than among their respective controls (16 vs 9\%, $P=0.04$ ), whereas no difference was observed between cases with angina pectoris and their controls. The difference observed in the group of hard CHD events was seen only in Northern Ireland (data not shown).

We next explored the combined effect of the two polymorphisms on coronary risk (Figure 1). Since, in the literature, TLR4/Gly ${ }^{299}$ has been shown to be associated with a blunted response of monocytes to LPS ${ }^{6}$ and CD14/ CC with a lower density of CD14 receptors on monocytes and lower sCD14 plasma levels, ${ }^{16,17,24}$ individuals who carry both genotypes might be expected to have a decreased sensitivity to LPS and, hence, to be at lower risk of CHD. However, when we analysed the two polymorphisms in combination in a logistic regression model, neither did we find any evidence for an interaction between them ( $P=0.94$ for the interaction) nor did we observe a significant decreased risk in individuals carrying both the Gly $^{299}$ allele and the CC genotype compared to all others $(\mathrm{RR}=1.40 ; P=0.33)$. However, it should be noted that the group of individuals carrying both the Gly ${ }^{299}$ allele and the CC genotype was small $(n=34)$ and that the study might lack power to detect such an interaction. When the CD14/ C-260T polymorphism was replaced by sCD14 concentrations in the model, the interaction with the TLR4 polymorphism did not reach significance either $(P=0.28)$.

\section{Discussion}

Several recent studies have suggested that the TLR4/Gly ${ }^{299}$ allele might confer a protective effect against atherosclerosis and its complications. This allele has been associated with a lower risk of carotid atherosclerosis in a populationbased survey, ${ }^{7}$ a decreased risk of acute coronary events in a case-control study, ${ }^{8}$ and a lower incidence of cardiovascular events in the REGRESS study, a prospective cholesterol-lowering trial in subjects with documented coronary artery disease. ${ }^{9}$ However, it should be stressed that in the REGRESS study, the protective effect of the Gly ${ }^{299}$ allele was 
Table 5 Mean levels of inflammatory and endothelial parameters according to CD14/C-260 T and TLR4/Asp299Gly genotypes

\begin{tabular}{|c|c|c|c|c|c|c|c|c|c|c|c|}
\hline Genotype & $\begin{array}{c}s C D 14(\mu g / \\
m l)\end{array}$ & $C R P^{\mathrm{a}}(\mathrm{mg} / \mathrm{l})$ & $1 L \sigma^{a}(p g / m l)$ & $1 L 18^{\mathrm{a}}(\mathrm{pg} / \mathrm{ml})$ & $T N F \alpha^{a}(p g / m l)$ & $\begin{array}{l}\text { Fibrinogen } \\
(\mathrm{mg} / \mathrm{ml})\end{array}$ & $s T M^{\mathrm{a}}(\mathrm{ng} / \mathrm{ml})$ & $s / C A M-1^{a}(n g / m l)$ & $\operatorname{sVCAM}-1^{\mathrm{a}}(\mathrm{ng} / \mathrm{ml})$ & $\begin{array}{c}f-T F P I(n g / \\
m()\end{array}$ & $\begin{array}{c}\begin{array}{c}v W F(I U / \\
m l)\end{array} \\
\text { ml }\end{array}$ \\
\hline \multicolumn{12}{|l|}{ CD14/C-260T } \\
\hline CC $(n=157)$ & $1.49(0.03)$ & $1.79(1.54-2.08)$ & $1.61(1.46-1.79)$ & $207.6(190.0-226.8)$ & $3.93(3.68-4.19)$ & $3.54(0.07)$ & $39.3(37.3-41.3)$ & $603.1(580.4-626.8)$ & $764.5(729.9-800.6)$ & $18.2(0.42)$ & $1.20(0.03)$ \\
\hline CT $(n=275)$ & $1.53(0.03)$ & $1.75(1.56-1.97)$ & $1.50(1.39-1.62)$ & $227.0(212.0-243.1)$ & $3.80(3.62-3.99)$ & $3.50(0.05)$ & $38.7(37.2-40.3)$ & $612.0(594.6-630.0)$ & $816.1(788.1-845.1)$ & $18.5(0.32)$ & $1.24(0.02)$ \\
\hline$\Pi(n=138)$ & $1.58(0.04)$ & $1.40(1.19-1.63)$ & $1.40(1.26-1.56)$ & $222.2(2.02 .8-243.4)$ & $4.01(3.75-4.29)$ & $3.49(0.07)$ & $43.5(41.2-46.0)$ & $608.3(584.9-632.7)$ & $859.4(819.6-901.1)$ & $18.5(0.45)$ & $1.21(0.03)$ \\
\hline$P$-value & 0.16 & 0.04 & 0.18 & 0.29 & 0.44 & 0.86 & 0.003 & 0.84 & 0.003 & 0.86 & 0.44 \\
\hline Homogeneity & 0.25 & 0.09 & 0.02 & 0.70 & 0.48 & 0.60 & 0.98 & 0.78 & 0.25 & 0.10 & 0.04 \\
\hline \multicolumn{12}{|l|}{$\begin{array}{l}\text { between } \\
\text { populations }\end{array}$} \\
\hline TLR4/Asp299Gly & & & & & & & & & & & \\
\hline $\begin{array}{l}\text { Asp/Asp } \\
(n=502)\end{array}$ & $1.54(0.02)$ & $1.68(1.54-1.82)$ & $1.50(1.42-1.59)$ & $219.8(209.1-231.1)$ & $3.92(3.78-4.06)$ & $3.51(0.04)$ & $40.0(30.8-41.2)$ & $609.1(596.4-622.1)$ & $818.2(797.4-839.6)$ & $18.38(0.24)$ & $1.22(0.02)$ \\
\hline Gly+ $(n=64)$ & $1.46(0.05)$ & $1.60(1.26-2.03)$ & $1.52(1.30-1.78)$ & $224.0(195.1-257.1)$ & $3.65(3.30-4.04)$ & $3.51(0.10)$ & $39.5(36.4-42.9)$ & $611.0(575.8-648.4)$ & $771.9(718.1-829.8)$ & $18.97(0.65)$ & $1.26(0.05)$ \\
\hline$P$-value & 0.10 & 0.70 & 0.86 & 0.80 & 0.20 & 0.94 & 0.78 & 0.92 & 0.14 & 0.39 & 0.40 \\
\hline $\begin{array}{l}\text { Homogeneity } \\
\text { between } \\
\text { populations }\end{array}$ & 0.60 & 0.85 & 0.60 & 0.56 & 0.81 & 0.56 & 0.46 & 0.13 & 0.89 & 0.68 & 0.13 \\
\hline
\end{tabular}

sCD14 = soluble CD14; CRP =C-reactive protein; IL-6=interleukin-6; IL-18=interleukin-18; TNF- $\alpha=$ tumour necrosis factor- $\alpha$; sTM =soluble thrombomodulin; sICAM-1 = soluble intercellular adhesion molecule-1; sVCAM-1 = soluble vascular cell adhesion molecule-1; $f-T F P I=$ free-tissue factor pathway inhibitor-1; vWF $=$ von Willebrand factor. Means (SEM) were adjusted for population and case-control status.

${ }^{a}$ For log-transformed variables, geometric means $(95 \% \mathrm{Cl})$ are given.

Table 6 Genotype and allele frequencies of the CD14/C-260 T and TLR4/Asp299Gly polymorphisms in men with and without a CHD event during the follow-up period

\begin{tabular}{|c|c|c|c|c|c|c|c|c|c|c|}
\hline & \multirow{2}{*}{\multicolumn{2}{|c|}{ All }} & \multicolumn{4}{|c|}{ By population } & \multicolumn{4}{|c|}{ By type of events } \\
\hline & & \multirow[b]{2}{*}{$\begin{array}{l}\text { Cases }^{a} \\
N(\%)\end{array}$} & \multicolumn{2}{|c|}{ France } & \multicolumn{2}{|c|}{ Northern Ireland } & \multicolumn{2}{|c|}{ Hard CHD } & \multicolumn{2}{|c|}{ Angina pectoris } \\
\hline & $\begin{array}{l}\text { Controls } \\
N(\%)\end{array}$ & & $\begin{array}{l}\text { Controls } \\
N(\%)\end{array}$ & $\begin{array}{l}\text { Cases } \\
N(\%)\end{array}$ & $\begin{array}{l}\text { Controls } \\
N(\%)\end{array}$ & $\begin{array}{l}\text { Cases } \\
N(\%)\end{array}$ & $\begin{array}{l}\text { Controls } \\
N(\%)\end{array}$ & $\begin{array}{l}\text { Cases } \\
N(\%)\end{array}$ & $\begin{array}{l}\text { Controls } \\
N(\%)\end{array}$ & $\begin{array}{l}\text { Cases } \\
N(\%)\end{array}$ \\
\hline \multicolumn{11}{|l|}{ CD14/C-260T } \\
\hline $\mathrm{CC}$ & $129(26)$ & $73(29)$ & $64(28)$ & $36(31)$ & $65(24)$ & $37(28)$ & $69(27)$ & $43(34)$ & $61(25)$ & $31(25)$ \\
\hline CT & $235(48)$ & $116(47)$ & $107(48)$ & $55(48)$ & $128(48)$ & $61(45)$ & $113(45)$ & $59(46)$ & $124(51)$ & $58(47)$ \\
\hline$\pi$ & $128(26)$ & $60(24)$ & $54(24)$ & $24(21)$ & $74(28)$ & $36(27)$ & $71(28)$ & $26(20)$ & $58(24)$ & $34(28)$ \\
\hline Allele freq $(\mathrm{C} / \mathrm{T})$ & $0.50 / 0.50$ & $0.53 / 0.47$ & $0.52 / 0.48$ & $0.55 / 0.45$ & $0.48 / 0.52$ & $0.50 / 0.50$ & $0.50 / 0.50$ & $0.57 / 0.43$ & $0.51 / 0.49$ & $0.49 / 0.51$ \\
\hline$P$-value & \multirow{2}{*}{\multicolumn{2}{|c|}{$\begin{array}{c}0.34 \\
0.88(0.61-1.27) \\
0.84(0.56-1.27)\end{array}$}} & \multirow{2}{*}{\multicolumn{2}{|c|}{$\begin{array}{c}0.40 \\
0.92(0.55-1.55) \\
0.79(0.42-1.47)\end{array}$}} & \multirow{2}{*}{\multicolumn{2}{|c|}{$\begin{array}{c}0.60 \\
0.84(0.50-1.42) \\
0.87(0.50-1.51)\end{array}$}} & \multirow{2}{*}{\multicolumn{2}{|c|}{$\begin{array}{c}0.08 \\
0.85(0.52-1.38) \\
0.60(0.33-1.07)\end{array}$}} & \multirow{2}{*}{\multicolumn{2}{|c|}{$\begin{array}{c}0.70 \\
0.91(0.52-1.58) \\
1.14(0.63-2.05)\end{array}$}} \\
\hline $\begin{array}{l}R R^{b} \text { for genotype } C T \\
R R^{b} \text { for genotype } T T\end{array}$ & & & & & & & & & & \\
\hline \multicolumn{11}{|l|}{ TLR4/Asp299Gly } \\
\hline Asp/Asp & $439(89)$ & $211(85)$ & $201(90)$ & $102(89)$ & $238(89)$ & $109(82)$ & $230(91)$ & $108(84)$ & $213(88)$ & 105 (87) \\
\hline Asp/Gly & $50(10)$ & $35(14)$ & $22(10)$ & $13(11)$ & $28(10)$ & $22(17)$ & $22(9)$ & $19(15)$ & $28(11)$ & $16(13)$ \\
\hline Gly/Gly & $1(1)$ & $1(1)$ & 0 & 0 & $1(1)$ & $1(1)$ & 0 & $1(1)$ & $1(1)$ & $0(0)$ \\
\hline Allele freq (Asp/Gly) & $0.95 / 0.05$ & $0.92 / 0.08$ & $0.95 / 0.05$ & $0.94 / 0.06$ & $0.94 / 0.06$ & $0.91 / 0.09$ & $0.96 / 0.04$ & $0.92 / 0.08$ & $0.94 / 0.06$ & $0.93 / 0.07$ \\
\hline $\begin{array}{l}\text { P-value }{ }^{c} \\
\text { RR }^{b} \text { for genotype Gly+ }\end{array}$ & \multicolumn{2}{|c|}{$\begin{array}{c}0.10 \\
1.46(0.93-2.30)\end{array}$} & \multicolumn{2}{|c|}{$\begin{array}{c}0.67 \\
1.17(0.58-2.37)\end{array}$} & \multicolumn{2}{|c|}{$\begin{array}{c}0.08 \\
1.72(0.94-3.14)\end{array}$} & \multicolumn{2}{|c|}{$\begin{array}{c}0.04 \\
2.00(1.03-3.87)\end{array}$} & \multicolumn{2}{|c|}{$\begin{array}{c}0.78 \\
1.09(0.58-2.08)\end{array}$} \\
\hline
\end{tabular}

Two cases had both types of events (ie angina pectoris then hard CHD) during follow-up and were included together with their respective matched controls ( $n=4$ ) in both hard CHD and angina pectoris groups.

${ }^{b} \mathrm{RR}(95 \% \mathrm{Cl})$ were calculated by reference to the most frequent genotype (CC or Asp/Asp).

${ }^{\mathrm{C}}$ Rare homozygotes for the Gly ${ }^{299}$ allele were pooled with heterozygotes for test. 


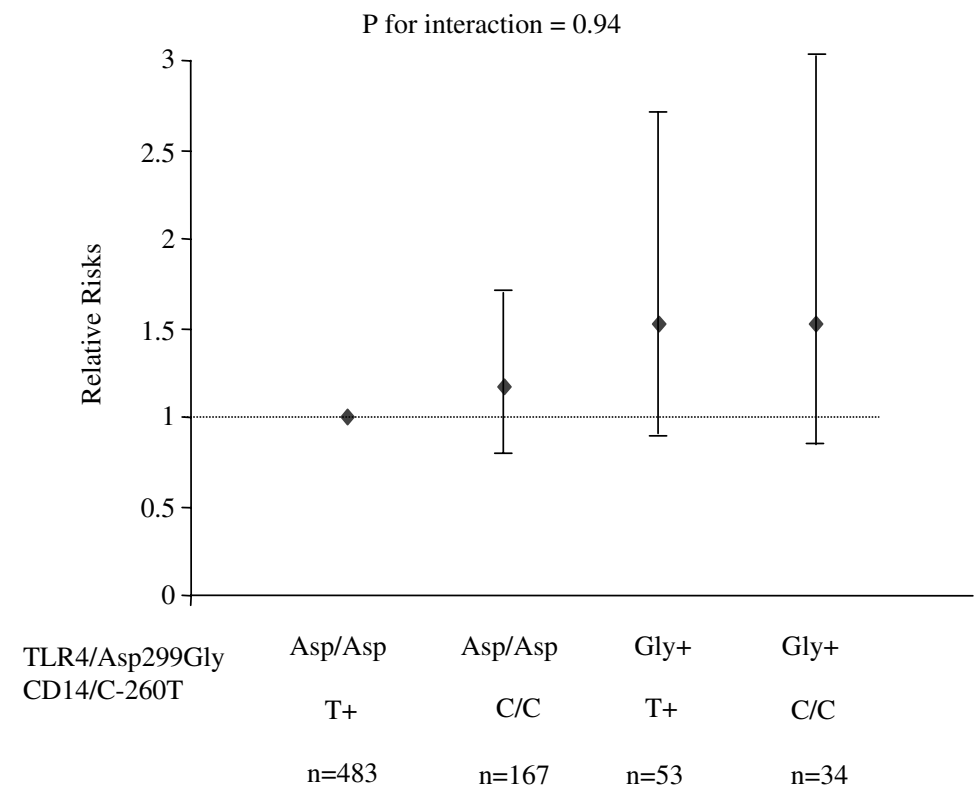

Figure 1 RR $(95 \%$ Cl) for coronary event according to the combination of TLR4/Asp299Gly genotype and CD14/C-260T genotype. The combination of the Asp/Asp and $\mathrm{T}+$ genotypes was taken as the class of reference.

not observed in the entire cohort but was confined to the group treated with pravastatin. ${ }^{9}$ In the present study, assessing for the first time the effect of the TLR4/ Asp299Gly polymorphism in a prospective cohort of initially healthy subjects, we could not confirm the protective effect of the Gly ${ }^{299}$ allele on coronary risk. The power of the present study for detecting an RR of 0.5 in carriers of the $\mathrm{Gly}^{299}$ allele (who represent $10 \%$ of the population) was 0.63 , so we cannot exclude that the study was underpowered to detect such an effect, and a fortiori a weaker effect. However, data from the present study rather suggest that the Gly ${ }^{299}$ allele is associated with an increased - and not decreased - risk of coronary events, a finding at variance with previous results. Since this effect was observed only in the population from Northern Ireland and not in France, and it concerns only hard CHD events (MI or coronary death) and not angina pectoris, it has to be interpreted with caution. Further prospective studies are required to gain more insight into the role of the Gly ${ }^{299}$ allele on cardiovascular risk in various clinical settings.

The TLR4 polymorphism is thought to play a role in atherosclerosis through modulation of expression of proinflammatory cytokines. Carriers of the $\mathrm{Gly}^{299}$ allele have been shown to have lower plasma concentrations of IL-6, fibrinogen or sVCAM-1 than individuals with the Asp/ Asp genotype. ${ }^{7,8}$ In the present study, we evaluated numerous inflammatory and endothelial markers but did not find any relationship with the TLR4 polymorphism.

Besides the TLR4, the endotoxin-sensing complex includes another LPS receptor, CD14. This receptor exists in a soluble form (sCD14) and a membrane-bound form
(mCD14). Few data are available on the association between sCD14 and the risk of coronary disease. In a large case-control study, plasma sCD14 levels did not differ between individuals with stable angina pectoris and controls. $^{24}$ The present prospective study did not provide evidence for an association of SCD14 with a future coronary event in a cohort of healthy men. Moreover, individuals with hard coronary events during follow-up had plasma sCD14 concentrations similar to those of cases suffering from angina pectoris. Paradoxically, sCD14 concentrations were increased in the high-risk population of Northern Ireland compared to France, as also observed for lipid variables and inflammatory markers (CRP, fibrinogen, IL6, IL18). ${ }^{31,32,35}$

It has been suggested that sCD14 plays a role in innate immunity by promoting the response of endothelial cells that do not express mCD $14 .^{12}$ This hypothesis is supported in the present study by the correlation observed between plasma concentrations of sCD14 and endothelial markers such as sICAM-1 and sTM. Given the strong relationship between sCD14 and acute-phase reactants, sCD14 might be responsible at least in part for the endothelial dysfunction observed during the inflammatory process. Plasma concentrations of sCD14 have been shown to be increased in individuals with diabetes, independent of CRP levels, suggesting that $\mathrm{sCD} 14$ per se might play a role in endothelial dysfunction observed in diabetes. A potential functional role of the CD14/C-260T has been suggested as it alters an Sp1 transcription factor binding site and modulates the activity of the promoter, the $\mathrm{T}$ allele being associated with higher transcription. ${ }^{36}$ Consistent with this 
finding, the T allele has been found to be associated with increased plasma SCD14 concentration or CD14 density on monocytes in some ${ }^{16,17,24}$ but not all studies. ${ }^{19,20}$ The present study confirmed a mildly increasing effect of the $\mathrm{T}$ allele on sCD14 levels. This allele was also associated with higher levels of endothelial cell markers such as sTM and sVCAM-1. Conversely, CRP levels were lower in the presence of this allele.

This result is unexpected since, in the presence of the -260T allele, monocytes are predicted to have higher levels of CD14 on their surface and hence to be more sensitive to activation.

In the PRIME Study, the CD14/C-260T polymorphism was not associated with future coronary events. The power of the study for detecting an RR of 1.5 associated with the T allele was 0.95 , so it is unlikely to be a problem of lack of power. This lack of association is in accordance with the negative results of the prospective evaluation of the CD14 polymorphism on the risk of future MI in the Physicians' Health Study. ${ }^{23}$ Given the potential interaction between TLR4 and CD14 in mediating signal transduction of innate immunity, we hypothesized that the CD14 polymorphism or plasma sCD14 concentrations might modify the relation between TLR4 polymorphism and the risk of coronary event. Since in the literature, the TLR $4 / \mathrm{Gly}^{299}$ allele is associated with a blunted response by monocytes to LPS ${ }^{6}$ and the CD14/CC genotype is associated with a lower density of CD14 receptors on monocytes ${ }^{17}$ and lower sCD14 plasma levels, ${ }^{16,24}$ individuals who carry both genotypes should be less sensitive to LPS than others, and hence at lower risk of CHD. However, this hypothesis was not supported by the present data.

In conclusion, this prospective study conducted in healthy individuals failed to find any association between TLR4 polymorphism, CD14 polymorphism or plasma sCD14 concentrations and the risk of future coronary events. The importance of both sCD14 and CD14 polymorphism should however not be dismissed, given their impact on the levels of other molecules that have been related to the atherosclerotic process, such as sTM and sVCAM-1.

\section{Acknowledgements}

We are indebted to Mrs J Ansaldi, A Bescond and M Billerey for their technical assistance with this project. We thank the following organisations, which allowed the recruitment of the PRIME subjects: the Health screening centres organised by the Social Security of Lille (Institut Pasteur), Strasbourg, Toulouse and Tourcoing; Occupational Medicine Sevices of Haute-Garonne, of the Urban Community of Strasbourg; the association Inter-entreprises des Services Médicaux du Travail de Lille et environs; the Comité pour le Développement de la Médecine du Travail; the Mutuelle Générale des PTTT du Bas-Rhin; the Laboratoire d'Analyses de l'Institut de Chimie Biologique de la Faculté de Médecine de Strasbourg; the Department of Health (NI) and the Northern Ireland Chest Heart and Stroke Association. The present work was supported by a grant from the Fondation de France.

\section{References}

1 Libby P: Inflammation in atherosclerosis. Nature 2002; 420: 868-874.

2 Binder CJ CM, Shaw PX, Miller YI, Hartvigsen K, Dewan A, Witztum JL: Innate and acquired immunity in atherogenesis. Nat Med 2002; 8: 1218-1226.

3 Medzhitov R, Janeway Jr C: Innate immunity. N Engl J Med 2000; 343: $338-344$.

$4 \mathrm{Xu}$ Q: Role of heat shock proteins in atherosclerosis. Arterioscler Thromb Vasc Biol 2002; 22: 1547-1559.

5 Edfeldt K, Swedenborg J, Hansson GK, Yan ZQ: Expression of tolllike receptors in human atherosclerotic lesions: a possible pathway for plaque activation. Circulation 2002; 105: 1158-1161.

6 Arbour NC, Lorenz E, Schutte BC et al: TLR4 mutations are associated with endotoxin hyporesponsiveness in humans. Nat Genet 2000; 25: 187-191.

7 Kiechl S, Lorenz E, Reindl $\mathrm{M}$ et al: Toll-like receptor 4 polymorphisms and atherogenesis. $N$ Engl J Med 2002; 347: $185-192$.

8 Ameziane N, Beillat T, Verpillat P et al: Association of the Toll-like receptor 4 gene Asp299Gly polymorphism with acute coronary events. Arterioscler Thromb Vasc Biol 2003; 23: e61-e64.

9 Boekholdt SM, Agema WR, Peters RJ et al: Variants of toll-like receptor 4 modify the efficacy of statin therapy and the risk of cardiovascular events. Circulation 2003; 107: 2416-2421.

10 Yang IA, Holloway JW, Ye S: TLR4 Asp299Gly polymorphism is not associated with coronary artery stenosis. Atherosclerosis 2003; 170: $187-190$.

11 Dobrovolskaia MA, Vogel SN: Toll receptors, CD14, and macrophage activation and deactivation by LPS. Microbes Infect 2002; 4: 903-914.

12 Ziegler-Heitbrock HW, Ulevitch RJ: CD14: cell surface receptor and differentiation marker. Immunol Today 1993; 14: 121-125.

13 Wright SD: Toll, a new piece in the puzzle of innate immunity. J Exp Med 1999; 189: 605-609.

14 Haziot A, Ferrero E, Kontgen F et al: Resistance to endotoxin shock and reduced dissemination of Gram-negative bacteria in CD14-deficient mice. Immunity 1996; 4: 407-414.

15 Chow JC, Young DW, Golenbock DT, Christ WJ, Gusovsky F: Tolllike receptor-4 mediates lipopolysaccharide-induced signal transduction. J Biol Chem 1999; 274: 10689-10692.

16 Baldini M, Lohman IC, Halonen M et al: A Polymorphism* in the $5^{\prime}$ flanking region of the CD14 gene is associated with circulating soluble CD14 levels and with total serum immunoglobulin E. Am J Respir Cell Mol Biol 1999; 20: 976-983.

17 Hubacek JA, Rothe G, Pit'ha J et al: C(-260) $\rightarrow$ T polymorphism in the promoter of the CD14 monocyte receptor gene as a risk factor for myocardial infarction. Circulation 1999; 99: 3218-3220.

18 Koch W, Kastrati A, Mehilli J, von Beckerath N, Schomig A: CD14 gene $-159 \mathrm{C} / \mathrm{T}$ polymorphism is not associated with coronary artery disease and myocardial infarction. Am Heart J 2002; 143: 971-976.

19 Unkelbach K, Gardemann A, Kostrzewa M et al: A new promoter polymorphism in the gene of lipopolysaccharide receptor CD14 is associated with expired myocardial infarction in patients with low atherosclerotic risk profile. Arterioscler Thromb Vasc Biol 1999; 19: $932-938$

20 Shimada K, Watanabe Y, Mokuno H et al: Common polymorphism in the promoter of the CD14 monocyte receptor gene is associated with acute myocardial infarction in Japanese men. Am J Cardiol 2000; 86: 682-684, A688.

21 Elghannam H, Tavackoli S, Ferlic L et al: A prospective study of genetic markers of susceptibility to infection and inflammation, and the severity, progression, and regression of coronary atherosclerosis and its response to therapy. J Mol Med 2000; 78: $562-568$.

22 Risley P, Jerrard-Dunne P, Sitzer M et al: Promoter polymorphism in the endotoxin receptor (CD14) is associated with increased carotid atherosclerosis only in smokers: the Carotid 
Atherosclerosis Progression Study (CAPS). Stroke 2003; 34: 600-604

23 Zee RY, Lindpaintner K, Struk B, Hennekens CH, Ridker PM: A prospective evaluation of the CD14 C(-260)T gene polymorphism and the risk of myocardial infarction. Atherosclerosis 2001; 154: $699-702$.

24 Koenig W, Khuseyinova N, Hoffmann MM et al: CD14 C(-260) $\rightarrow$ T polymorphism, plasma levels of the soluble endotoxin receptor CD14, their association with chronic infections and risk of stable coronary artery disease. J Am Coll Cardiol 2002; 40: 34-42.

25 Nauck M, Winkelmann BR, Hoffmann MM et al: C(-260)T polymorphism in the promoter of the CD14 gene is not associated with coronary artery disease and myocardial infarction in the Ludwigshafen Risk and Cardiovascular Health (LURIC) study. Am J Cardiol 2002; 90: 1249-1252.

26 Amar J, Ruidavets JB, Bal Dit Sollier C et al: Soluble CD14 and aortic stiffness in a population-based study. J Hypertens 2003; 21: $1869-1877$.

27 Yarnell JW, The PRIME study: classical risk factors do not explain the severalfold differences in risk of coronary heart disease between France and Northern Ireland. Prospective Epidemiological Study of Myocardial Infarction. Qjm 1998; 91 : 667-676.

28 Tunstall-Pedoe H, Kuulasmaa K, Amouyel P et al: Myocardial infarction and coronary deaths in the World Health Organization MONICA Project. Registration procedures, event rates, and casefatality rates in 38 populations from 21 countries in four continents. Circulation 1994; 90: 583-612.

29 Ducimetiere P, Ruidavets JB, Montaye M, Haas B, Yarnell J: Fiveyear incidence of angina pectoris and other forms of coronary heart disease in healthy men aged 50-59 in France and Northern Ireland: the Prospective Epidemiological Study of Myocardial Infarction (PRIME) Study. Int J Epidemiol 2001; 30: 1057-1062.

30 Luc G, Arveiler D, Evans A et al: Circulating soluble adhesion molecules ICAM-1 and VCAM-1 and incident coronary heart disease: the PRIME Study. Atherosclerosis 2003; 170: 169-176.

31 Luc G, Bard JM, Juhan-Vague I et al: C-Reactive Protein, Interleukin-6, and Fibrinogen as Predictors of Coronary Heart Disease: The PRIME Study. Arterioscler Thromb Vasc Biol 2003; 23: $1255-1261$.

32 Blankenberg S, Luc G, Ducimetiere P et al: Interleukin-18 and the risk of coronary heart disease in European men: the Prospective Epidemiological Study of Myocardial Infarction (PRIME). Circulation 2003; 108: 2453-2459.

33 Morange PE, Simon C, Alessi MC et al: Endothelial cell markers and the risk of coronary heart disease: the Prospective Epidemiological Study of Myocardial Infarction (PRIME) study. Circulation 2004; 109: 1343-1348.

34 Miller SADD, Polesky HF: A simple salting out procedure for extracting DNA from human nucleated cells. Nucleic Acids Res 1988; 16: 1215.
35 Scarabin PY, Arveiler D, Amouyel P et al: Plasma fibrinogen explains much of the difference in risk of coronary heart disease between France and Northern Ireland. The PRIME study. Atherosclerosis 2003; 166: 103-109.

36 LeVan TD, Bloom JW, Bailey TJ et al: A common single nucleotide polymorphism in the CD14 promoter decreases the affinity of Sp protein binding and enhances transcriptional activity. J Immunol 2001; 167: 5838-5844.

\section{Appendix A1. The PRIME Study Group}

The PRIME Study is organised under an agreement between INSERM and the Merck, Sharpe and Dohme-Chibret Laboratory, with the following participating Laboratories:

The Strasbourg MONICA Project, Department of Epidemiology and Public Health, Faculty of Medicine, Strasbourg, France (D Arveiler, B Haas).

The Toulouse MONICA Project, INSERM U558, Department of Epidemiology, Paul Sabatier-Toulouse Purpan University, Toulouse, France (J Ferrières, JB Ruidavets).

The Lille MONICA Project, INSERM U508, Institut Pasteur de Lille, France (P Amouyel, M Montaye).

The Department of Epidemiology and Public Health, Queen's University Belfast, Northern Ireland (A Evans, J Yarnell).

The Department of Atherosclerosis, INSERM UR545, Lille, France (G Luc, JM Bard, L Elkhalil, JC Fruchart).

The Hematology Laboratory, CHU Timone, Inserm U626, Faculty of Medecine, Marseille, France (I JuhanVague).

The Laboratory of Endocrinology, INSERM U326, Toulouse, France (B Perret).

The Vitamin Research Unit, The University of Bern, Bern, Switzerland (F Gey).

The Trace Element Laboratory, Department of Medicine, Queen's University Belfast, Northern Ireland (D. McMaster, J Woodside, I Young).

The DNA Bank, INSERM U525, Paris, France (F Cambien).

The Coordinating Center, INSERM U258, Paris-Villejuif, France (P Ducimetière, A Bingham). 